\begin{tabular}{|c|c|c|}
\hline \multicolumn{3}{|c|}{ Jurnal Warna : Jurnal Pendidikan Dan Pembelajaran Anak Usia dini. } \\
& Maret 2020. Vol 05. No. 01 \\
\hline Received: Januri 2020 & Accepted: Februari 2020 & Published: Maret 2020 \\
\hline & Article DOI: $10.24903 /$ jw.v5i1.13 \\
\hline
\end{tabular}

\title{
PEMBENTUKAN KARAKTER BAGI ANAK USIA 5-6 TAHUN MELALUI LAGU-LAGU ANAK DITK IT BUNGA HARAPAN SAMARINDA
}

\author{
Nurwati \\ Program Studi PIAUD IAIN Samarinda \\ nurwatinir123@gmail.com \\ Aisyah Salsabila \\ Program Studi PIAUD IAIN Samarinda \\ aisyah190297@gmail.com
}

\begin{abstract}
Abstrak
Penelitian ini bejudul "Pembentukan Karakter bagi Anak Usia 5-6 Tahun Melalui Lagu-lagu Anak di TK IT Bunga Harapan Samarinda”. Pembentukan karakter bagi anak melalui lagu sangatlah berpengaruh. Pentingnya untuk mengajarkan lagu-lagu yang sesuai anak usia dini agar karakter mereka tumbuh dengan baik. Lagu-lagu yang ada di Taman Kanak-kanak IT Bunga Harapan Samarinda diperuntukkan untuk menanamkan nilai karakter yang bermoral, serta sikap yang mencerminkan rasa kepedulian, kedisiplinan dan rasa tanggung jawab pada diri anak. Nilai-nilai karakter inilah yang dituangkan ke dalam lagu dan kemudian dapat diterapkan anak pada kehidupan sehari-hari. Tujuan penelitian ini ialah untuk mengetahui pembentukan karakter anak melalui lagu-lagu anak yang terdapat di TK IT Bunga Harapan, dan lagu-lagu seperti apa saja yang diberikan agar dapat membentuk karakter yang baik pada diri anak di TK IT Bunga Harapan Samarinda.Jenis penelitian ini adalah penelitian atau lapangan dengan pendekatan deskriptif kualitatif. Subjek penelitian ini adalah kepala sekolah, guru, dan murid di TK IT Bunga Harapan Samarinda. Metodologi penelitian yang digunakan yaitu deskriptif kualitatif. Metode pengumpulan data menggunakan observasi, wawancara, dan dokumentasi. Tehnik analisis data menggunakan reduksi data, penyajian data dan aplikasi data. Keabsahan data menggunakan tringulasi.Hasil penelitian ini menunjukkan bahwa pembentukan karakter bagi anak usia 5-6 tahun melalui lagu-lagu anak di TK IT Bunga Harapan menunjukkan dari lagu- lagu yang diterapkan sudah dapat membentuk karakter tanggung jawab, disiplin, dan kepedulian, menyesuaikan lagu sesuai dengan tema pembelajaran. Lagu yang mengandung nilai-nilai karakter adalah lagu Berwudhu, lagu hujan, lagu profesi, lagu aku Seorang Muslim, lagu Baca Hamdalah, lahu Santri Kecil, lagu Beres-beres, dan lagu Recalling.
\end{abstract}

Kata Kunci; Karakter, Lagu-lagu Anak

Abstract

The research is entitled "Character Building for Children 5-6 Years Old Through Children's Songs at Kindergarten IT Flower Hope Samarinda". Forming characters for children through songs is very influential. It is important to teach songs that are appropriate for early childhood so that their characters grow well. The songs that are in Kindergarten IT Flower Hope Samarinda are intended to instill moral character values, as well as attitudes that reflect a sense of caring, discipline and a sense of responsibility in children. These character values are poured into songs and can then be applied to children in everyday life. The purpose of this study was to determine the formation of children's characters through children's songs in TK Bunga Harapan Kindergarten, and what kind of songs are given in order to form good characters in children in TK Bunga Harapan Kindergarten Samarinda.This type of research is research or field with a qualitative descriptive approach. The subjects of this study were the principal, teachers, and students at the Bunga Harapan Kindergarten IT Samarinda. The research methodology used is descriptive qualitative. Data collection methods use observation, interviews, and documentation. Data analysis techniques use data reduction, data presentation and 
Jurnal Warna : Jurnal Pendidikan Dan Pembelajaran Anak Usia dini. Maret 2020. Vol 05. No. 01

Received: Januri $2020 \quad$ Accepted: Februari 2020

data applications. The validity of the data uses tringulation.The results of this study indicate that the formation of characters for children aged 5- 6 years through children's songs in TK IT Bunga Harapan shows that the songs that are applied can shape the character of responsibility, discipline, and caring, adjusting songs in accordance with the theme of learning. Songs that contain character values are ablution songs, rain songs, professional songs, I am a Muslim song, Baca Hamdalah song, Lahu Santri Kecil, Clearing song, and Recalling song.

Keywords; Characters, Children's Songs 


\begin{tabular}{|c|c|c|}
\hline \multicolumn{3}{|c|}{ Jurnal Warna : Jurnal Pendidikan Dan Pembelajaran Anak Usia dini. } \\
Maret 2020. Vol 05. No. 01 \\
\hline Received: Januri 2020 & Accepted: Februari 2020 & Published: Maret 2020 \\
\hline & Article DOI: 10.24903/jw.v5i1.13 \\
\hline
\end{tabular}

\section{Pendahuluan}

Pendidikan anak usia dini dapat diartikan sebagai usaha sadar dan terencana untuk mewujudkan suasana belajar dan proses pembelajaran kepada anak usia 0 sampai dengan 6 tahun secara aktif dan kreatif agar memiliki kecerdasan emosional dan spiritual, serta kecerdasan intelektual yang diperlukan bagi dirinya, masyarakat, bangsa dan Negara.(Novan Ardi Wiyani, $2016: 1$ )

Agar pertumbuhan dan perkembangan anak dapat berkembang dengan optimal, guru harus mampu menanamkan nilai dasar pendidikan karakter seperti nilai sikap, agama, budi pekerti, sopan santun, kasih sayang dan mengarahkan anak untuk berperilaku positif dalam kehidupan sehari-hari sehingga karakter positif dan baik dapat tertanam pada anak sejak usia dini. Adapun nilai-nilai karakter dasar yang perlu ditanamkan sejak usia dini antara lain kesopanan, kasih sayang, keindahan, bersahabat, kepatuhan, kedisiplinan, dan kemandirian. (Sri Wahyuningsih, 2017).

Menurur Joseph Murphy dalam artikelnya berjudul Pengembangan Karakter mengatakan bahwa dalam diri manusia terdapat satu pikiran yang memiliki ciri yang berbeda. Berdasarkan ciri tersebut, pikiran dibedakan atas dua macam, yaitu pikiran sadar (objektif) dan pikiran bawah sadar (subjektif). Sedang Ellen Galinsky dan Deborah Philips dalam Enni K. Hairuddin, megemukakan bahwa anak-anak sekarang perlu mendapat pondasi hidup yang lebih penting daripada sekedar tahu huruf dan angka. Anak-anak perlu di latih tiga hal, yaitu working memory, inhibitory control dan mental flexibility seperti yang ditulis Renald Khasali dalam SINDO News. (Enni K. Hairuddin, 2014:6)

Pendidikan karakter bukan saja dapat membuat seorang anak mempunyai akhlak yang mulia, melainkan dapat meningkatkan keberhasilan akademiknya. Beberapa hasil penelitian menunjukkan bahwa terdapat hubungan erat antara keberhasilan pendidikan karakter dengan keberhasilan akademik serta perilaku prososial anak. Melalui pendidikan karakter ini anak usia dini disiapkan untuk meningkatkan mutu penyelenggaraan dan hasil pendidikan di sekolah yang mengarah pada pencapaian pembentukan karakter dan akhlak mulia peserta didik secara utuh, terpadu, seimbang, dan sesuai dengan standar kompetensi lulusan. ( Anita Ahsanah, 2018)

Pendidikan karakter pada anak usia dini merupakan pendidikan yang melibatkan penanaman pengetahuan, kecintaan, dan penanaman perilaku kebaikan yang menjadikan sebuah 


\begin{tabular}{|c|c|c|}
\hline \multicolumn{3}{|c|}{ Jurnal Warna : Jurnal Pendidikan Dan Pembelajaran Anak Usia dini. } \\
Maret 2020. Vol 05. No. 01 \\
\hline Received: Januri 2020 & Accepted: Februari 2020 & Published: Maret 2020 \\
\hline & Article DOI: 10.24903/jw.v5i1.13 \\
\hline
\end{tabular}

kebiasaan. Pendidikan karakter tidak lepas dari nilai-nilai dasar yang di pandang baik.

Lagu-lagu islmi merupakan salah satu stimulasi dalam mengenalkan nilainilai karakter. Melalui kegiatan bernyanyi akan lebih efektif karena musik akan lebih mudah diinterpretasi oleh otak anak serta akan cenderung bertahan lebih lama dalam ingatannya. Bernyanyi merupakan salah satu kegiatan yang sering digunakan dalam pendidikan dan pembelajaran bagi anak usia dini, dan lagu sebagai medianya. (Anita Ahsanah, 2018)

Taman Kanakkanak IT Bunga Harapan Samarinda terbiasa setiap paginya memberikan anak-anak stimulasi melalui lagu-lagu asmaul husna, dan lagu-lagu islami pada saat anak baru memasuki gerbang sekolah. Sebelum memulai kegiatan sentra, anak-anak terbiasa berbaris yang rapi dan memulai doa pagi. Doa pagi yang berikan kepada anak ialah doa yang disertai dengan bersenandung, dengan begitu anak dapat mengingat do'a dengan mudah dan dapat menarik minat anak untuk berdoa. Anak-anak sangat disiplin pada saat berdoa bersama. Setelah berdoa anak- anak diberikan stimulus lagulagu harian seperti lagu "Tepuk Anak Sholeh, Tepuk Semangat, Kepak-kepak, serta Siapakah Tuhanmu” dan lain-lain, sambil menggerakan tubuh bersama-sama.
Hal ini yang menarik perhatian peneliti untuk meneliti tentang pembentukan karakter anak yang dimulai melalui lagu-lagu anak di TK IT Bunga Harapan. Pembentukan yang disebutkan disini ialah anak ditanamkan tentang mengerti baik dan buruk, mengerti tindakan apa yang harus diambil, dan mampu memberikan prioritas yang baik. Dalam hal ini peneliti berpusat pada penelitian tentang pembentukan karakter yang dapat dilakukan melalui lagu-lagu anak. Lagu-lagu yang dapat membentuk karakter anak diantaranya seperti lagu bangun tidur, asmaul husna, mengenal keluarga nabi, guruku tersayang, dll. Kemudian peneliti memfokuskan pada 3 karakter yang di nilai dapat menstimulasi anak, yaitu; tanggung jawab, kedisiplinan, serta kepedulian. Karena mengingat pembentukan karakter pada anak usia dini itu sangatlah penting, maka peneliti tertarik untuk melakukan penelitian, dengan judul "Pembentukan Karakter bagi Anak Usia 5-6 Tahun Melalui Lagu-lagu Anak di TK IT Bunga Harapan Samarinda".

\section{Metode Penelitian}

Penelitian ini adalah penelitian lapangan atau field work research, karena yang diteliti adalah sesuai yang ada dilapangan secara langsung. Dalam hal ini yang dijadikan objek penelitian adalah TK IT Bunga Harapan Samarinda. Penelitian 


\begin{tabular}{|c|c|c|}
\hline \multicolumn{3}{|c|}{ Jurnal Warna : Jurnal Pendidikan Dan Pembelajaran Anak Usia dini. } \\
\hline \multicolumn{3}{|c|}{ Maret 2020. Vol 05. No. 01 } \\
\hline Received: Januri 2020 & Accepted: Februari 2020 & Published: Maret 2020 \\
\hline & Article DOI: 10.24903/jw.v5i1.13 \\
\hline
\end{tabular}

ini menggunakan penelitian kualitatif, yaitu penelitian yang temuannya tidak diperoleh melalui prosedur statistik atau bentuk hitungan lainnya.

Subjek penelitian ini adalah guru di TK IT Bunga Harapan Samarinda, yang berjumlah 2 tenaga pengajar dan peserta didik yang berjumlah 17 anak. Guru TK IT Bunga Harapan Samarinda merupakan pelaku pembentukan karakter, sehingga dari guru dapat diperoleh informasi dan data penelitian yang dimaksud. Peserta didik merupakan sasaran dari pembentukan karakter, sedangkan kepala sekolah yang memiliki kebijakkan tentang pembentukan karakter bagi anak usia 5-6 tahun melalui lagu-lagu anak di TK IT Bunga Harapan Samarinda.

Sumber data data dalam penelitian ini adalah data Primer yang diperoleh peneliti adalah Kepala Sekolah, Guru kelas Sentra Balok, Guru kelas Sentra Persiapan, peserta didik. Guru sebanyak 2 orang dan peserta didik sebanyak 17 anak.Dan data Sekunder yang tidak langsung memberikan data kepada pengumpul data, misalnya lewat orang tua atau dokumendokumen.

Untuk mengumpulkan berbagai data yang diperlukan dalam penelitian ini, digunakan metode-metode sebagai berikut: Observasi, Wawancarara, dan dokumentasi.
Penelitian yang dilaksanakan di TK IT Bunga Harapan Samarinda, menggunakan analisis data deskriptif kualitatif .Adapun teknik untuk pemeriksaan keabsahan data, sesuai menurut Lexy J. Moleong mengatakan ada 6 yaitu perpanjangan keikutsertaan, ketekunan pengamatan, trianggulasi, pengecekan sejawat, kecukupan referensial, kajian kasus negatif, auditing.

Trigulasi adalah cara yang dilakukan oleh peneliti dengan recheck dan crosscheck, peneliti melakukan pemeriksaan data mengulang memeriksanya dan dilakukan pemeriksaan dengan mengkonfirmasi dengan sumber, tehnik dan waktu lain dengan upaya ini maka dijamin data yang diperoleh absah. Kecukupan referensial dimaksudkan untuk memperbanyak bahan-bahan referensi. Dengan banyaknya refersi maka terdapat banyak rujukan yang menjadi pertimbangan dalam memberi penilaian terhadap data. Bahan referensial adalah foto dan dokumen autentik. (Sugiyono, 85)

\section{Hasil dan pembahasan}

1. Nilai Karakter dalam Lagu "Tepuk Anak Sholeh"

Ketika anak-anak semuanya sudah memasuki sekolah, disini guru menerapkan pembiasaan disiplin tanpa harus bersuara keras. Biasanya guru akan mulai 


\begin{tabular}{|c|c|c|}
\hline \multicolumn{3}{|c|}{ Jurnal Warna : Jurnal Pendidikan Dan Pembelajaran Anak Usia dini. } \\
Maret 2020. Vol 05. No. 01 \\
\hline Received: Januri 2020 & Accepted: Februari 2020 & Published: Maret 2020 \\
\hline & Article DOI: 10.24903/jw.v5i1.13 \\
\hline
\end{tabular}

membunyikan bel melalui toak yang tersedia di sekolah. Pada saat anak mendengar bunyi toak tersebut, maka mereka akan refleks berbaris di lapangan sekolah. Anak-anak akan berbaris dengan rapi dan tertib. Di TK IT Bunga Harapan, anak-anak terbiasa membaca doa pagi bersama-sama. Lalu menyenandungkan Asmaul Husna. Setelahnya guru memulai segala aktivitas di sekolah.

$\begin{array}{cccc}\text { Lagu "Tepuk Anak } & \text { Sholeh" } \\ \text { mengajarkan } & \text { kepada } & \text { anak } & \text { tentang }\end{array}$
memberikan motivasi bahwa jika ingin menjadi anak yang sholeh harus menaati kewajiban- kewajibannya sebagai umat muslim yaitu, dengan rajin sholat dan mengaji serta mencintai Islam sampai akhir hayatnya. Lagu ini juga membangkitkan semangat kepada anak, karena selain liriknya yang bernilai positif dan memiliki pesan moral, nadanya pun penuh keceriaan dan semangat. Lagu ini diberikan pada saat anak- anak melakukan kegiatan baris berbaris di lapangan sekolah sebelum memulai semua aktivitas yang ada di sekolah.

2. Nilai Karakter dalam Lagu "Siapakah Tuhanmu"

Siapakah Tuhanmu yang memiliki nilai pembentukan karakter keingintahuan anak tentang mengenal Allah SWT, Nabi Muhammad SAW, agama Islam, dan kitab Al-Qur'an. Lagu Siapakah Tuhanmu Pada bait pertama mengajarkan tentang pembentukan karakter keingitahuan kepada anak bahwa sebutan Tuhan bagi umat Islam ialah Allah SWT. Mengenalkan agama Islam yang telah dianut, dan mengenalkan Nabi Muhammad, Nabi utusan Allah dan mengenalkan kitab orang Islam, yaitu AlQur'an. Dengan lebih mengenal Allah, agama islam, Nabi, serta kitab Al-Qur'an. Anak-anak secara tidak langsung belajar bagaimana caranya mencintai Allah, yaitu dengan berbuat baik, bertutur kata yang baik. Serta melaksanakan kewajiban sebagi umat muslim yaitu sholat lima waktu dan rajin dalam mengaji. Lagu inipun diberikan kepada anak pada saat kegiatan baris-berbaris di lapangan. Lagulagu inilah yang menjadi pembuka utama agar anak-anak bersemangat dalam kegiatan sekolah.

3. Nilai Karakter dalam Lagu "Berwudhu" Anak-anak di TK IT Bunga Harapan terbiasa setiap paginya melaksanakan sholat Dhuha. Sebelum berwudhu,mengajarkan kepada anak tentang aturan berwudhu, mulai dari tangan sampai kaki. Tentang bersuci diri setiap akan melaksanakan kewajiban umat muslim seperti sholat ataupun mengaji. Kemudian TK IT Bunga Harapan juga melalui lagu Berwudhu mengajarkan dan menerapkan kepada anak tentang tata tertib dan disiplin. Langkah-langkah dalam 


\begin{tabular}{|c|c|c|}
\hline \multicolumn{3}{|c|}{ Jurnal Warna : Jurnal Pendidikan Dan Pembelajaran Anak Usia dini. } \\
Maret 2020. Vol 05. No. 01 \\
\hline Received: Januri 2020 & Accepted: Februari 2020 & Published: Maret 2020 \\
\hline & Article DOI: 10.24903/jw.v5i1.13 \\
\hline
\end{tabular}

berwudhu yang harus berurutan, tidak sesuka hati dan semau anak. Seperti halnya peneliti mendapatkan data yang menyatakan bahwa:

Dari lagu berwudhu inilah dapat dilihat karakter disipllin anak yang dibentuk serta dimunculkan secara bertahap, seperti anak mulai mengetahui kewajiban seorang muslim dalam mensucikan diri sebelum melaksanakan sholat dan mengaji. Anak akan terbiasa berperilaku disiplin. Melakukan wudhu pada saat-saat tertentu, seperti sebelum sholat dan sebelum mengaji. (Arsiah, 2019)

\section{Nilai Karakter dalam Lagu "Profesi"}

Lagu-lagu yang diberikan guru untuk anak adalah lagu yang memiliki pesan nilai karakter di dalamnya serta disesuaikan dengan tema yang ada, tujuan lagu diberikan pada awal kegiatan ialah sebagai penambah motivasi semangat anak dalam memulai pembelajaran. Seperti halnya peneliti mendapatkan data yang menyatakan bahwa:

Sebagai guru dalam memberikan lagu-lagu anak sebaiknya dapat menyesuaikan dengan tema yang ada, tetapi terkadang ada lagu yang muncul secara spontan dari guru, gunanya membuat mood anak untuk tidak cepat bosan di dalam kegiatan pembelajaran. Pemberian lagu pun harus memiliki pesan moral serta nilai-nilai pembentukan karakter. Agar anak selain bersemangat karakter positifnya pun terbentuk dengan baik. (Arsiah, 2019)

Lagu Profesi adalah lagu yang menyesuaikan dengan tema pembelajaran yang sedang berlangsung di TK IT Bunga Harapan, dan yang menyesuaikan dengan tema yaitu terdapat pada judul serta lirik lagunya, pesan yang terkandung di dalam lagu, yang memuat nilai pembentukan karakter anak melalui lagu ialah anak di perkenalkan berbagai macam profesi pekerjaan dan tanggung jawab dalam menjalankan tugas di setiap masingmasing pekerjaan.

\section{Nilai Karakter dalam Lagu "Hujan"}

Lagu-lagu spontan yang memuat nilai pembentukan karakter tanggung jawab yang sering diberikan oleh guru pada anak di TK IT Bunga Harapan, lagunya ialah sebagai berikut:

Judul: Hujan

Hujan-hujan alangkah senangnya Mengenakan jas huja Pakai payung berwarnaAyo kawan ikutlah serta Hujan bukanlah halangan Pergi sekolahHujan bukanlah halangan Pergi mengaji. (ita Ariani, 2019)

6. Nilai Karakter dalam "Lagu Aku Seorang Muslim"

Lagu yang membentuk karakter disiplin, yang berjudul Aku Seorang Muslim. Lagu "Aku Seorang Muslim" menguatkan hati dengan mengucapkan dua kalimat syahadat sebagai pengakuan bahwa Tiada Tuhan selain Allah dan Muhammad adalah utusan Allah.

7. Nilai Karakter dalam Lagu "Baca Hamdallah"

Pada lagu "Baca Hamdallah" terdapat bagian bait pertama yang mengajarkan dan mengingatkan kepada 


\begin{tabular}{|c|c|c|}
\hline \multicolumn{3}{|c|}{ Jurnal Warna : Jurnal Pendidikan Dan Pembelajaran Anak Usia dini. } \\
Maret 2020. Vol 05. No. 01 \\
\hline Received: Januri 2020 & Accepted: Februari 2020 & Published: Maret 2020 \\
\hline & Article DOI: 10.24903/jw.v5i1.13 \\
\hline
\end{tabular}

anak untuk tidak lupa mengucap Alhamdulillah sebagai rasa syukur setelah melakukan perbuatan baik. Bait kedua memberi arahan kepada anak agar selalu mengingat semua pesan-pesan ustadzah terutama pesan ustadzah yang mengingatkan membaca Alhamdulillah setelah melakukan perbuatan baik, sebagai tanda rasa syukur. Lagu ini juga terdapat nilai pembentukan karakter disiplin yang dapat ditemukan hampir di semua lirik. Jadi maksud dari keseluruhan kalimat yang terdapat dilirik lagu tersebut ialah anak diajarkan untuk selalu disiplin pada saat setiap melakukan segala aktivitas dengan tidak lupa berdo'a membaca Hamdallah, dan selalu mengingat pesan yang baik dari gurunya.

\section{Nilai Karakter dalam Lagu "Santri Kecil"}

Penyebutan ustadzah adalah panggilan untuk guru di TK IT Bunga Harapan, maka dari itu lagu ini diubah liriknya sedikit pada bagian ingat slalu pesan ustadzah. Dengan demikian lagu ini memiliki lirik pembentukan nilai karakter disiplin yang seringkali di ajarkan dan diterapkan di TK IT Bunga Harapan. Seperti lagu berikut, yang nadanya familiar di kalangan anak-anak tetapi juga memiliki pesan moral serta pembentukan nilai-nilai karakter kepedulian.
9. Nilai Karakter dalam Lagu "Beresberes"

Pada saat kegiatan akhir kelas sentra. Ketika anak-anak selesai melakukan kegiatan sentra dan sehabis bermain, guru biasanya memberikan stimulasi dalam membentuk karakter pada diri anak melalui lagu tentang nilai pembentukan karakter bertanggung jawab.

10. Nilai Karakter dalam Lagu "Recalling"

Ketika guru mulai menyenandungkan lagu Recalling, anak-anak akan refleks mengambil tas mereka dan bersiap-siap untuk pulang, dengan duduk yang rapi dan tertib sambil mengikuti senandung "Recalling” bersama-sama. Kemudian anak-anak terlihat mulai satu persatu menceritakan kejadian dan kegiatan apa saja hari ini yang dilakukan di sekolah. lagunya sebagai berikut:

Judul: Recalling

Recalling recalling Ayo kita recalling Cerita cerita apa yang dilakukan

11. Nilai Karakter dalam Lagu "Sebelum Pulang Sekolah"

Lirik lagu Sebelum Pulang Sekolah ini mencakup tiga nilai pembentukan karakter sekaligus, yaitu nilai karakter disiplin, tanggung jawab, dan nilai karakter kepedulian.

Proses pembentukan karakter anak melalui lagu-lagu anak. Guru 


\begin{tabular}{|c|c|c|}
\hline \multicolumn{3}{|c|}{ Jurnal Warna : Jurnal Pendidikan Dan Pembelajaran Anak Usia dini. } \\
& Maret 2020. Vol 05. No. 01 \\
\hline Received: Januri 2020 & Accepted: Februari 2020 & Published: Maret 2020 \\
\hline & Article DOI: $10.24903 /$ jw.v5i1.13 \\
\hline
\end{tabular}

memasukkan nilai-nilai karakter ke dalam lirik lagu-lagu anak sesuai dengan apa yang sudah dijelaskan sebelumnya, peneliti memfokuskan pada tiga nilai karakter, yaitu; 1) tanggung jawab, 2) disipllin, dan 3) kepedulian. Peneliti menemukan hasil dilapangan bahwa TK IT Bunga Harapan bukan hanya memberntuk karakter tanggung jawab, disiplin, dan kepedulian akan tetapi juga banyak membentuk karakter moral dari lirik lagu-lagu yang ada. Seperti yang dijelaskan dari Kompas menyebutkan bahwa:

"Lirik lagu anak usia dini yakni menggunakan kata-kata sederhana dan tidak terlalu panjang (terutama lagu yang mengandung nilai pendidikan karakter dan moral), boleh panjang asalkan mengandung sebuah cerita yang menarik dan mudah dipahami anak-anak. Makna dari lirik lagu sebagai pembentuk karakter sesuai dengan aspek perkembangan yang akan dibentuk oleh pendidik. Lagu yang sudah diterapkan dalam lembaga pendidikan merupakan lagu yang memiliki makna pembentukan karakter dasar bagi anak usia dini."(Dwi Wahyu Riwanti, Hardika, Umi Dayati,2017)

Pembentukan karakter tanggung jawab dalam setiap lagu yang diterapkan di TK IT Bunga Harapan Samarinda untuk terbiasa bersih dan rapi seperti merapikan mainan mereka sehabis bermain sampai benar-benar bersih, hal ini dilakukan agar anak dapat bertanggung jawab ketika selesai melakukan segala sesuatu.

Pembentukan karakter anak melalui lagu-lagu anak menggunakan nada lagu yang familiar dikalangan anak-anak. Nada lagu yang dikenal anak-anak, nada lagunya pun sederhana dan mudah di ingat dan dilafalkan. Memilih nada lagu yang familiar kemudian disesuaikan dengan lirik lagu yang ada. Hal ini senada dengan pendapat Rosediana, bahwa:

Lagu anak-anak itu seharusnya memiliki ciri nadanya cenderung lucu atau bit nya memang khas. Meski lagunya agak mellow (empuk dan lembut) seperti lagu "Kasih Ibu" tetap saja ada kekhasan di dalamnya tidak terlalu 'rock', 'metal', atau seperti lagu-lagu 'pop'. Nada lagu sebaiknya, ada yang dapat dipadukan dengan gerakan atau tepukan tangan, dan tetap khas sesuai dengan jiwa anak-anak. Dan dari sisi interval lagu anak-anak menggunakan interval yang sangat sederhana sehingga dapat memudahkan anak-anak dalam menyanyikan lagu tersebut. Ini merupakan hal yang harus diperhatikan di sekolah. Untuk memahami dan berlatih materi lagu harus sesuai dengan kapasitas suara anak-anak di usia dini. (Ardipal, 2015) 


\begin{tabular}{|c|c|c|}
\hline \multicolumn{3}{|c|}{ Jurnal Warna : Jurnal Pendidikan Dan Pembelajaran Anak Usia dini. } \\
& Maret 2020. Vol 05. No. 01 \\
\hline Received: Januri 2020 & Accepted: Februari 2020 & Published: Maret 2020 \\
\hline & Article DOI: $10.24903 /$ jw.v5i1.13 \\
\hline
\end{tabular}

Hal ini sangat mempengaruhi pada pembentukan karakter melalui lagu-lagu anak pada anak sejak usia dini. Semakin anak menyukai nada lagu yang disampaikan, maka anak akan lebih mudah dalam menyerap pesan-pesan moral serta dapat memahami makna dari lagu tersebut. Dan hal ini dapat dimanfaatkan sebagai penunjang untuk membentuk karakter yang baik pada diri anak. Anak akan lebih mudah dibentuk karakternya menggunakan lagu- lagu yang mereka sukai, nada-nada lagu yang ceria, dan lirik yang sesuai dengan pemahaman anak.

\section{Kesimpulan dan Saran}

Berdasarkan hasil penelitiana yang dilakukan peneliti pada kelompok $\mathrm{B}^{3}$ Ibnu Musa di dua sentra, yaitu sentra balok dan sentra persiapan di TK IT Bunga Harapan dapat disimpulkan bahwa; Keseluruhan lagulagu yang telah diberikan dan ditanamkan dalam proses pembentukan karakter bagi anak usia 5-6 tahun melalui lagu-lagu anak di TK IT Bunga Harapan sudah menunjukkan bahwa dari lagu-lagu yang diterapkan sudah dapat membentuk karakter tanggung jawab, disiplin, dan kepedulian, menyesuaikan lagu sesuai dengan tema pembelajaran, dan lagu yang mengandung nilai-nilai karakter seperti lagu Berwudhu, Hujan, Profesi, Aku Seorang Muslim, Baca Hamdallah, serta Santri Kecil, yang di berikan pada saat kegiatan outdoor.

Dari simpulan disarankan agar guru hendaknya melakukan evaluasi pembelajaran tentang lagu-lagu yang sudah diajarkan pada kegiatan akhir kelas sentra, agar mengetahui keefektifan pelaksanaan program stimulasi dan pencapaian hasil oleh setiap anak. Hendaknya setiap guru menguasai lagu-lagu serta dapat memberikan inovasi terhadap berbagai jenis lagu agar anak tidak mudah bosan.

\section{Daftar Pustaka}

Anita Ahsanah, Implementasi Nilai Karakter Melalui Metode Bernyanyi Untuk Anak Usia Dini di TK Satya Dharma Sudjana Kecamatan Bandar Mataram Kabupaten Lampung Tengah. Skripsi, Fakultas Tarbiyah dan Keguruan Universitas Islam Negeri Raden Intan Lampung, 2018.

Andrianto, Tuhana Taufiq. Mengembangkan Karakter Sukses Anak di Era Cyber, Jogjakarta: Ar-Ruzz Media, 2011.

Ardipal, "Kembalikan Lagu Anak-anak Indonesia: Sebuah analisis Struktur Musik", dalam Jurnal Panggung no. 4, Vol. XXV, 2015.

Dwi Wahyu Riwanti, Hardika, Umi Dayati, "Pemahaman Pendidik tentang Makna Lagu Anal-anak sebagai Pembentuk Karakter Anak Usia Dini", dalam Jurnal Ilmu Pendidikan no. 2, Vol. II, 2017. 


\begin{tabular}{|c|c|c|}
\hline \multicolumn{3}{|c|}{ Jurnal Warna : Jurnal Pendidikan Dan Pembelajaran Anak Usia dini. } \\
& Maret 2020. Vol 05. No. 01 \\
\hline Received: Januri 2020 & Accepted: Februari 2020 & Published: Maret 2020 \\
\hline & Article DOI: $10.24903 /$ jw.v5i1.13 \\
\hline
\end{tabular}

Hairuddin, Enni K. Membentuk Karakter Anak dari Rumah, Jakarta: PT Elex Media Komputindo, 2014.

Sugiyono. Metode Penelitian Pendidikan Pendekatan Kuantitatif, Kualitatif, dan $R \& D$, Bandung : Alfabeta, 2012.

Sujiono, Yuliani Nurani. Konsep Dasar Pendidikan Anak Usia Dini, Cet. 6, Jakarta: PT Indeks Permata Puri Media, 2013. 